\title{
Adult Social \& Emotional Learning: Establishing Campus Cultures of Well-Being
}

\author{
Dr. Terry A Silver \\ The University of Tennessee at Martin \\ 239C Gooch Hall \\ Martin, TN USA
}

\begin{abstract}
Safe and comfortable classroom environment and positive teacher-student relationships encourage academic learning and social emotional learning (SEL). In addition, after incorporating SEL into classrooms and schools, teachers' social-emotional abilities and health status significantly affect learning conditions. Research has been consistent in showcasing the benefits to students, teachers, and schools in which SEL is prioritized. Specific practices facilitated by the teacher in the classroom provide smoother transitions and secure, predictable classrooms. These practices can jointly lay a solid foundation of safety, consistency and joy in classrooms.
\end{abstract}

Keywords:Social Emotional Learning, teacher-student relationships, social-emotional competence.

\section{Introduction}

In the United States coronavirus cases have toppled 1 million and are now thought to be a pandemic. Although there is great concern surrounding the coronavirus, there is another pressing pandemic with more than 20 million abused, neglected, and traumatized children in the United States. The abuse, neglect, and trauma leaves children at risk to mental, physical, and emotional problems. If left untreated, these problems will lead to substance abuse, antisocial, and criminal behavior and eventual school failure. Our society has yet to recognize this epidemic, or even consider developing an immunization strategy (Child Trauma Academy \& Linkletter Media, 2003). As teachers on the front line in classrooms every day, there must be a push to foster resilience and empowerment into the lives of children. The human body, mind, and soul have remarkable capacity to take the challenges of abuse and trauma and create richer and more meaningful life experiences. Caring adults can make a huge difference since students spend a majority of their time in school. Educators have tremendous power to further complicate or even re-traumatize at school or help children find ways to arm themselves with social and emotional learning competencies. Teachers can promote practices in their own lives that will influence students in the classroom.

\section{Literature Review}

One in five teachers feel tense about their job all or most of the time, compared to one in eight workers in similar professions (Ross, 2016). This results in fewer teacher candidates entering the field in teaching and more teachers quitting earlier on in their careers. Working intensively over fewer weeks in the year leads to a poorer work-life balance and higher stress levels among teachers according to Ross, 2016.Mary Bousted (2019), joint secretary of the National Education Union said: "When faced with impossible workloads, endless accountability, a testing culture run riot, and flat or underfunded pay deals year after year, it is all too common for good teachers to leave the profession." Forty-six percent of teachers report high daily stress levels on par with nurses and just above doctors (45\%) (Bousted, 2019). Teachers and nurses had the highest levels of reported stress among occupational groups (Sparks \&Malkus, 2015). Educators and school staff find their work "always" or "often" stressful 61\% of the time, significantly higher than workers in the general population, who report that work is "always" or "often" stressful only 30\% of the time (American Federation of Teachers, 2017). What impact does this have in the classroom on students who are themselves dealing with anxiety, sleep problems and/or depression? The effects can be tremendous for students who spend most of day in a classroom under the supervision of these teachers.

Teacher's social and emotional learning competence (SELC) and well-being strongly influence the learning context and the infusion of social emotional learning into classrooms and schools (Collaborative for Academic, Social, and Emotional Learning, 2012). In addition, teachers SELC influence classroom organization and management (Mashburnet al., 2008). Maintaining a calm, organized, and well-regulated classroom environment is essential. Such environments include effective behavior management approaches as well as practices that encourage creativity, student choice and autonomy, and student reflection. Lombas et al. (2019), evaluated the efficacy of one program which intentionally sought to enhance personal and social development of students and to promote happiness in students, teachers, and families. Lombas et al. (2019) found programs such as The Happy Classrooms Program may promote psychological well-being, positive classroom climate, and reduce school aggression in students. Teachers' own social emotional learning competencies share the nature of their relationships with students (Jennings \& Greenberg, 2009). 
Merritt et. al. (2012), found classrooms with warm teacher-student relationships promote deep learning among students and students who feel comfortable with their teachers and peers are more willing to engage with challenging materials and persevere at difficult learning tasks. Not only do we need to infuse classrooms which meet face to face and in K-12 but we also need to do so in higher education. According to Fields (2020) "Assign self-care, and model it. Start a lecture with a mindful moment or share a mediation exercise with your students." Researchers and others strongly suggest the need for teachers to build their own social and emotional well-being and integrate into the fabric of K-18 education.

\section{Social and Emotional Learning Competencies}

Researchers, educators and child advocates met together at the Fetzer Institute in 1994 with the intention of finding ways to promote positive development in students. The term social and emotional learning and the formation of the Collaborative for Social, Emotional and Academic Learning (CASEL) emerged from the meeting. The Collaborative for Social, Emotional and Academic Learning states that social emotional learning is "the process by which students and adults acquire and effectively apply the knowledge, attitude, and skills necessary to understand and manage emotions, set and achieve positive goals, feel and show empathy for others, establish and maintain positive relationships and make responsible decisions (CASEL, 2015, p.3)".

In 2015, CASEL released the Handbook of Social and Emotional Learning: Research and Practice which includes research articles detailing foundations of SEL, evidence-based programs, assessment and widespread practice and policy. In the handbook, authors advocate for a systematic SEL infusion into all educational settings. Through "establishing a unifying framework based on a coordinated set of evidence-based practices for enhancing the social-emotional-cognitive development and academic performance of all students" (CASEL, Meyers et al., Zins, Weissberg, Wang \& Walberg, 2004, p. 22), students and adults can acquire and apply the knowledge, skills and attitudes daily to enhance well-being in all situations and settings.

\section{Signature Social and Emotional Learning Practices for the Classroom}

Making meaning from the research can be challenging and finding practical ways to infuse SELC in our classrooms might be daunting to some. However, there are three main categories of carefully chosen, effectively facilitated, and thoughtfully debriefed teaching practices working together to build a solid foundation of safety, consistency, and joy in classrooms. They are: Welcoming Routines \& Rituals, Engaging Pedagogy, and Optimistic Closure (adapted from the work of Ann McKay Bryson, CASEL Consultant). When used consistently, these three signature SEL practices create conditions for growth and learning across all five SEL competencies. By providing repetitive and engaging learning opportunities, they help students improve the skills and habits of:

- $\quad$ Self-awareness and social awareness through noticing and naming feelings and seeing how they are connected to what is happening within and around us.

- $\quad$ Self-management and relationship building, by interacting with people and with content in ways that intentionally strengthen our skillset of being aware of and in control of our thoughts, emotions, actions, and interactions.

- $\quad$ Focusing and persevering by balancing novelty with routines and rituals; we are internally soothed by sameness, while paradoxically, our brains are refreshed.

Incorporating the social and emotional learning competencies through the following signature SEL practices will provide rich and meaningful experiences for all students.

\section{Welcoming Rituals.}

Ritual openings establish safety and predictability, support contribution by all voices, set norms for respectful listening, allow students to connect with one another, and create a sense of belonging. To be successful with welcoming rituals, they must be carefully chosen, connected to the objectives for the subject/content, and facilitated with positive affect and enthusiasm. Some examples for the classroom include Class Circles or Morning Meetings where all voices are equal and heard. Check-ins are important to utilize to allow students to share what they are feeling or thinking before coursework begins. Check-ins can be helpful to gauge student readiness and interest. Community Building Exercises create a sense of safety and value in a classroom. These exercises might include an open-ended question to get students thinking or promote deep reflection. Other forms of community building include surveys where students can make choices and move to different parts of the classroom. Community Building activities can also be used to creatively assess prior learning. In addition to ritual openings in the classroom, it is important to include school-wide efforts. Welcoming Rituals may include adults showing joy when students come into the building, office counters holding baskets of breakfast items and instead of showing disappointment at late arrivals, showing signs of gladness that the student was able to come at all. These rituals establish warmth and a sense of value to students and adults. 


\section{Engaging Pedagogy.}

Engaging practices are brain-compatible strategies that can foster relationships, cultivate humility, responsiveness, empowerment and collaboration. They intentionally build social emotional learning skills. These practices include opportunities for brain breaks that provide time for integrating new information into long-term memory.

Teachers should balance opportunities for quiet reflection and writing with more active movement activities. Examples may include explicit teaching of SEL skills or Think-Pair-Share activities to help students make sense of new ideas and input. Brain-breaks are more commonly utilized in classrooms and allows students to stand and stretch, refresh and reset the brain and include movement and making connections. Engaging pedagogy maintains student attention and refreshes the brain so that learning becomes more meaningful.

\section{Optimistic Closure.}

Teachers can provide optimistic closures by ending the class/day on a positive note. Providing positive closure reinforces learning and can connect school to home. It can also create a sense of anticipation for the next day. Examples may include ending the day with reflection on what was most important in learning from the day. Students can reflect and share something they learned, someone they helped, something they would like to share at home, something they are looking forward to tomorrow, or something they enjoyed about the day. Optimistic closures provide students with reflection and a sense of looking forward.

A student's repeated experiences of safety, predictability, empowerment, collaboration, and reflection can be a powerful influence for rewiring of the neural pathways necessary for habits to be built and sustained. Having routines and rituals in classrooms and school communities are beneficial for each and every child and absolutely essential for some.

\section{Conclusion}

In order to create cultures of well-being on our school campuses, we must address social emotional learning competencies in our students and teachers. The positive connection between warm classroom environments and academic learning along with SEL competence gives us ample reason to incorporate signature practices into our classrooms. In a world where trauma is present in the lives of more students than ever before, it is time to consider self-management, self-awareness, social-awareness, relationship skills, and responsible decision-making as core components in classrooms. These competencies are critical for both students and those who work in schools to develop. With the inclusion of intentional signature practices, teachers, students, staff and administration can work together to build solid foundations of safety, consistency, and joy in classrooms.

\section{References}

American Federation of Teachers. (2017). 2017 Educator quality of work life survey (pp. 1-9). Washington, DC.

Bousted, Mary (2019). Teachers suffer more stress than other workers, study finds (pp. 1-4). Independent Digital News and Media Ltd, London, UK.

Collaborative for Academic, Social, and Emotional Learning. (2012). Effective social and emotional learning programs (pp. 1-80). Chicago, IL.

Field, K. (2020). 10 tips to support students in a stressful shift to online learning. The Chronicle of Higher Education, 8-11.

Jennings, P. A., \& Greenberg, M. T. (2009). The Prosocial Classroom: Teacher social and emotional competence in relation to student and classroom outcomes. Review of Educational Research, 79(1), 732-749.

Lombas, A. S., Jimenez, T. I., Arguis-Rey, R., Hernandez-Paniello, S., Valdivia-Salas, S., \& Martin-Albo, J. (2019). Impact of the Happy Classrooms Programme on psychological well-being, school aggression, and classroom climate. Mindfulness, 10(8), 1642-1660.

Mashburn, A. J., Pianta, R. C., Barbarin, O. A., Bryant, D., Hamre, B. K., Downer, J. T., ... Howes, C. (2008). Language and social skills. Child Development, 79(3), 732-749.

Merritt, E. G., Wanless, S. B., Rimm-Kaufman, S. E., Cameron, C., \&Peugh, J. L. (2012). School psychology review. School Psychology Review, 41(2), 141-159.

Perry, B. D., Child Trauma Academy, \& Linkletter Media (2003). Understanding traumatized and maltreated children: The six core concepts [Video recording]. Available from Aquarius Healthcare Videos.

Ross, N. (2016). School workforce in England: November 2016 (pp. 1-16). Kew, London: Department of Education.

Sparks, D., \&Malkus, N. (2015). Public school teacher autonomy in the classrooms across school years 2003-04, 2007-08, and 2011-12 (pp. 1-23). Washington, D.C.: National Center for Education Statistics. 